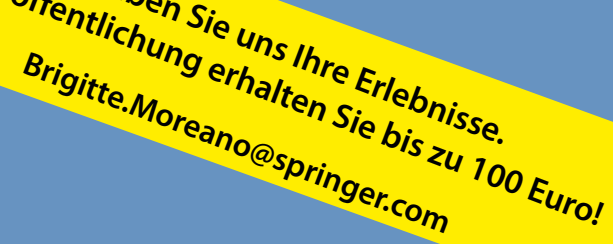

\title{
Das passt wohl nicht
}

den, um eine Verletzung zu vermeiden. Mit einiger Mühe ließ sich eine Kocherrinne zwischen Penis und Schraubenmutter schieben. Es dauerte etwa 30 Minuten, bis die Mutter auf einer Seite durchgesägt war. Aufbiegen ließ sie sich nicht. Also musste die Prozedur auf der gegenüberliegenden Seite wiederholt werden. Nach ungefähr einer Stunde harter Arbeit war die Schraubmutter endlich entfernt. Der Patient fiel mir um den Hals und verließ befreit und glücklich die Praxis.

Die Nachschau erfolgte am nächsten Tag - einem Sonntag. Der Patient bedankte sich mit einer Büchse Leberwurst und einer Büchse Bratwurst aus eigener Schlachtung.

Auf dem Notfallschein wurde die ärztliche Leistung mit den Ziffern für eine Nachtberatung und der Entfernung eines oberflächlichen Fremdkörpers abgerechnet.

Dr. med. Helmut WURChe, BACKNANG =
— Die Patientin kam von etwas weiter her, weil sie mich irgendwo in den Medien aufgetan hatte. Bei ihrer Terminvereinbarung wurden meine Damen schon stutzig, weil sie so begeistert von mir schwärmte. Nicht, dass die mich nicht für eine gute Ärztin hielten, aber so viele Lobeshymnen (und das im Voraus, ohne dass wir uns schon kennengelernt hätten) waren ihnen zurecht suspekt. Mir auch, denn ich weiß, dass ich solchen Vorschusslorbeeren kaum standhalten kann.

Nun war sie da, und es wurde so schwierig, wie wir befürchtet hatten. Sie schleppte ein riesiges Bündel psychosomatischer Lasten mit sich und hatte für alles und jedes Erklärungen parat, an denen sie auch nicht rütteln wollte. Alle anderen Ärzte hatten sie bitter enttäuscht. Nein, sie wisse zwar, dass sie ihren ungesunden Lebensstil ändern müsse, aber das könne sie nicht, sagte sie. Schließlich habe sie viel zu viel Stress dafür. Eine gründliche Untersuchung hätte sie vor Jahren das letzte Mal gemacht; der irre hohe Cholesterinspiegel damals hätte an ihrer Nascherei gelegen, die sie aber nicht än- dern wolle, schließlich brauche sie all das Süße. Medikamente nähme sie generell nicht, denn man wüsste ja, dass diese nicht gesund seien

Ich erklärte ihr freundlich aber fest, dass ich zwar manchmal ganz nett bin, aber nicht daran dächte, meine Zeit jemandem zu widmen, der so gar nicht zur Mitarbeit bereit wäre. Meine Kraft wäre mir zu schade dafür, um mich über schlechte Stoffwechselwerte zu ärgern, die ich nur dokumentieren, aber nicht korrigieren dürfe, weil weder gesunde Ernährung noch Medikamente akzeptiert würden. Dann bat ich sie, sich einen anderen Hausarzt zu suchen. Sie war noch sprachlos, als sie aus der Tür ging.

Warum war ich so kompromisslos? Weil sie nicht die erste war, mit der mir das passiert ist! Für meine eigene gute Stimmung habe ich mir versprochen, nichts Hoffnungsloses mehr zu beginnen, das mir die Kraft raubt. Die brauche ich noch für Patienten, die sich wenigstens ein Minimum an Mühe geben.

Dr. med. Frauke Höllering, ARnsberg =

\section{Belcanto in der Praxis}

\section{- Seit etlichen Jahren besuche ich einen Volkshochschulkurs Italienisch, weil ich gerne nach Italien fahre und weil ich dort Freunde gefunden habe, mit denen ich mich in ihrer Muttersprache unterhalten mag. Üben kann ich in meiner Praxis. Meine italienischen Patienten werden nur noch italienisch angesprochen.}

Als ein neuer Patient - nicht Angelo Branduardi und leider auch nicht Andrea Bocelli, jedoch an seinem Namen unschwer als Italiener zu identifizieren - mein Zimmer betritt, begrüße ich ihn mit einem herzlichen „Buon giorno", komme ins
Schwärmen, befrage inn auf Italienisch nach seinen Beschwerden ... und schaue in ein verständnisloses Gesicht.

"Frau Doktor", sagt er, „ische kanne überhaupt keine italienisch mehr ..."

Ob Italiener Angst vorm Blutabnehmen haben? Sagen wir mal so, ein paar von "meinen" Italienern schon. Zu diesen gehört auch ein junger Mann, ein giovanotto also, aus Neapel. Diese dunklen angsterfüllten Augen sind herzerweichend und ich frage mich, was tun? In diesen Fällen hilft oft singen und ich fange schon mal an (mit dem Blutabnahmeequipment hinter meinem Rücken): „Laciate mi cantare ...” sofort singt mein Patient weiter: "con la guitarra in mano ..." Die Strophe endet dann auf "italiano vero"(ein echter Italiener), was wir im Chor singen. Ich entdecke eine wunderbare Stimme, streite mich schnell, ob das Lied von Adriano Celentano oder Toto ist. Er hat recht, es ist von Toto und sein Blut habe ich längst abgenommen. Er hat nix gemerkt und heißt ab diesem Tag "bella voce" (schöne Stimme). Ich glaube, mittlerweile liebt er es, von mir Blut abgenommen zu bekommen.

DR. MED. LUISE HESS 